\title{
Contorno Norte: reflexos sobre o Conjunto Habitacional Requião em Maringá, PR, Brasil
}

\author{
Contorno Norte: reflejos en el Conjunto Habitacional Requião \\ de Maringá, PR, Brasil
}

\section{Contorno Norte: reflections on the Conjunto Habitacional Requião in Maringá, PR, Brazil}

\author{
Tatiana Kaori Abe \\ tkaoriabe@gmail.com \\ Universidade Estadual de Maringá, UEM, Maringá, PR \\ Priscilla Borgonhoni Chagas \\ priscillabchagas@gmail.com \\ Universidade Estadual de Maringá, UEM, Maringá, PR
}

Resumo: Este estudo analisou os reflexos da construção do Contorno Norte para os moradores do Conjunto Habitacional Requião na cidade média de Maringá, realizada com recursos do Programa de Aceleração do Crescimento (PAC). A intervenção viária trouxe consequências negativas para a população residente com a alteração no projeto inicial. Atrasos na execução, a falta de adaptabilidade às transformações locais e a não participação popular no processo de decisão sobre a construção da obra, conforme dita a lei para obras de grande impacto, são apontados como fatos resultantes da construção do Contorno. A obra se relacionou mais com os interesses em criar novos espaços de atuação do mercado imobiliário e privilegiar projetos idealizados pelo Poder Público.

Palavras-chave: Programa de Aceleração do Crescimento (PAC); Espaço Urbano; Estatuto da Cidade.

Resumen: Este estudio analizó los efectos de la construcción del Contorno Norte para los residentes del Conjunto Habitacional Requião de la ciudad media de Maringá, realizada con recursos del Programa de Aceleración del Crecimiento (PAC). La intervención viaria tuvo consecuencias negativas para la población residente en el barrio estudiado, ya que hubo un cambio en el proyecto inicial. Los retrasos en la ejecución, la falta de adaptabilidad a las transformaciones locales y la participación no popular en el proceso de toma de decisiones con respecto a la construcción de la obra, como lo dicta la ley para obras de gran impacto, se señalan como aspectos resultantes de la construcción del contorno. El trabajo estaba más relacionado con los intereses de crear nuevos espacios para el mercado inmobiliario y favorecer proyectos diseñados por el Gobierno.

Palabras clave: Programa de Aceleración del Crecimiento (PAC); Espacio Urbano; Estatuto de la Ciudad.

Abstract: This study analyzed the effects of Contorno Norte settlement for residents of the Requião Housing Complex in the medium city of Maringá, applying resources from the government Growth Acceleration Program (PAC). The road intervention had 
negative consequences for the neighborhood since there was a change in the initial project. Delays in execution, lack of adaptability to local transformations and nonpopular participation in the decision-making process about the construction of the work, as dictated by the law for high impact works, are pointed as aspects resulting from the construction of the Contour. The work was more related to the interests in creating new spaces for the real estate market and to favor projects designed by the Government.

Keywords: Growth Acceleration Program (PAC); Urban Space; City Statute.

\section{INTRODUÇÃO}

A pluralidade na concepção de cidade enquanto espaço de contrastes e de interesses, local de morada ou por sua capacidade de aglomerar as pessoas permite o vislumbre da cidade por diversas lentes, perfazendo um campo privilegiado para a compreensão dos fenômenos urbanos atuais, como também o processo de construção da sociedade. Nesse contexto entra em cena um importante conceito: o direito à cidade. Desenvolvido por Henri Lefebvre em 1968, o filósofo e sociólogo francês o define como um direito de não exclusão da sociedade urbana das qualidades e benefícios da vida urbana (LEFEBVRE, 2001). Diante disso, ele defende o direito à cidade como uma recuperação coletiva do espaço urbano por grupos marginalizados que vivem nos distritos periféricos da cidade. Num contexto mais recente, Harvey (2014), discorre sobre a influência dos movimentos sociais coletivos, tendo como objetivo zelar pelo direito à cidade e reivindicar a parte que compete aos cidadãos na tomada de decisões e respeito de como moldar o espaço.

Assim, o direito à cidade se volta como como um direito de não exclusão da sociedade urbana nas qualidades e benefícios da vida urbana, e está diretamente relacionado a mobilidade urbana, ou seja, a facilidade de deslocamento das pessoas e bens na cidade, tendo em vista a complexidade das atividades econômicas e sociais nela desenvolvidas (SEMOB, 2005). Esse e outros problemas urbanos estão se tornando uma questão administrativa, técnica, científica, já que os cidadãos, segundo Lefebvre (2001), estão se tornando mais objetos do que sujeitos do espaço social, o que é um reflexo das relações econômicas de dominação e de políticas urbanísticas controlados pelo Estado.

O Estado é um dos vários agentes produtores do espaço urbano, que utiliza de instrumentos mais amplos para atuar na produção do espaço, sendo um dos instrumentos enfatizados por lei, o Estatuto da Cidade (Lei № 10.257/2001), que tem por objetivo a garantia do direito à cidade como um dos direitos fundamentais das pessoas, assim, para que todos tenham acesso às oportunidades que a vida urbana oferece. Originado do Estatuto da Cidade, surge outro instrumento de planejamento urbano, o Plano Diretor, que define o que pode ser feito na cidade, bem como a indução de seu crescimento (COELHO, 2012).

Assim, para atender a demanda em relação a realidade atual das cidades brasileiras, o Governo Federal em 2007 implantou o Programa de Aceleração do Crescimento (PAC) como uma estratégia de desenvolvimento para o país e política econômica realizada a partir de programas de investimentos (CHAGAS; CARVALHO; MARQUESAN, 2015). 
O objetivo do governo era eliminar os principais déficits que impediam o crescimento econômico, viabilizando o aumento da produtividade das empresas, além do estímulo ao investimento privado e à redução das desigualdades regionais (RODRIGUES; SALVADOR, 2011). A cidade de Maringá possuía 25 empreendimentos inscritos no PAC no ano de 2015, distribuídos pelos eixos: Comunidade Cidadã; Minha Casa, Minha Vida; e Cidade Melhor (PAC, 2015).

Maringá surgiu no final da década de 1940, de forma planejada a alcançar 200.000 habitantes em 50 anos (RODRIGUES, 2004), no entanto em 2019 já passa dos 423.000 habitantes (IBGE, 2019). Nasceu a partir de um plano urbanístico, com representações simbólicas que enfatizam a sua imagem urbana e destacam um polo regional que se criava em uma região sem ocupação urbana anterior (ANDRADE; CORDOVIL, 2008). A cidade cresceu sem favelas, pois as que se formaram no decorrer da evolução da cidade tiveram seus moradores remanejados para municípios vizinhos ou para a periferia do perímetro urbano (STAHLHOEFER; RODRIGUES, 2010), obedecendo assim uma orientação que reproduziu no território processos de desigualdade social pela ação do mercado imobiliário (BORGES; SELA, 2013).

Com a expansão do perímetro urbano e a consolidação de Maringá como centro regional e a consequente aceleração do mercado imobiliário, houve a necessidade de adequações da infraestrutura urbana, principalmente viária, com finalidade de melhorar o tráfego e permitir um fluxo mais rápido e adequado da produção, dos serviços e das pessoas. Especificamente a Avenida Colombo, que é de responsabilidade federal, uma vez que faz parte da BR 376, continuou um problema na mobilidade da cidade, por conta de congestionamento diários, inúmeros acidentes e alto tráfego de veículos pesados. Para solucionar os problemas e transtornos nessa avenida, desenvolveu-se o projeto PAC Contorno Norte, com intuito de desviar carros e caminhões para os arredores da cidade (FONTANA; VALOTTA, 2012), cortando 38 setores censitários (IBGE, 2010), dentre eles o Conjunto Habitacional Requião, inaugurado na década de 199, com 26.114 moradores (IBGE, 2010).

Esse conjunto se constitui numa das maiores áreas urbanas precárias e periféricas da cidade de Maringá originadas da desfavelização das áreas mais centrais da cidade. Assim, este trabalho se debruçará em analisar os reflexos da obra Contorno Norte para os comerciantes e moradores deste conjunto habitacional através de pesquisa qualitativa descritiva empregando etapas documental, bibliográfica e entrevistas semiestruturadas como instrumento de coleta de dados. Foram realizadas entrevistas com oito comerciantes e moradores do Conjunto Habitacional.

\section{A PRODUÇÃO DO ESPAÇO URBANO E O DIREITO À CIDADE}

Segundo Corrêa (1999), os usos do espaço urbano definem áreas como atividades produtivas e sociais, articuladas por fluxos de circulação de pessoas e mercadorias, e relações espaciais envolvendo investimentos, mais-valia, circulação de decisões, e entre 
outras aquelas de reserva para futura expansão. Este conjunto de usos da terra consitui a organização espacial da cidade. O espaço urbano é fragmentado e articulado, reflexo e condicionante social, um conjunto de símbolos e campo de lutas (CORRÊA, 1999). Segundo Santos (1998) e Lefebvre (2001), o espaço urbano é o conteúdo, intimamente ligado à produção em geral; são as próprias relações sociais materializadas no espaço.

As cidades, como espaços hegemônicos de produção e troca de alto nível de concentração urbana, de aumento de população e de conjuntos de infraestrutura tornamse, assim, espaços no qual indivíduos e sociedade encontram-se mais vulneráveis a perdas advindas de processos variados, isto é, espaços de risco. Nestes espaços o risco também pode ocorrer frequentemente em função de características conflitantes das formas de ocupação e uso do solo e os processos produtivos/tecnológicos, sociais e 'naturais' que determinam situações de perdas potenciais ou efetivas. Deste modo, a apropriação e uso dos recursos naturais através de processos produtivos e a própria dinâmica dos processos da natureza e dos processos sociais tendem a gerar riscos à sociedade, relacionando-se à sua dinâmica socioespacial (SANTOS, 1998).

Segundo Pena (2014), é importante compreender que os termos urbano e cidade, apesar de serem corriqueiramente utilizados como sinônimos, podem designar elementos diferentes. $\mathrm{O}$ urbano refere-se às práticas que se diferenciam do rural no sentido de concentrar, preferencialmente, atividades relacionadas ao setor secundário (indústrias) e terciário (comércio e serviços), enquanto o rural é composto por áreas não ocupadas (como reservas florestais) e agrárias, que se especializam em práticas do setor primário (agropecuária, mineração e extrativismo). A cidade, por outro lado, é a materialização do urbano, com aglomerações populacionais e suas expressões (conjuntos de casas, prédios, áreas de lazer, etc.).

Ainda de acordo com Pena (2014), o processo de urbanização no território brasileiro iniciou-se, de maneira mais concreta, a partir do final do século XIX, com o início gradativo da industrialização no país. Porém, só após 1930 as indústrias se tornaram mais presentes e a urbanização se intensifica. A segunda metade do século XX atravessou intenso êxodo rural ocasionado pela mecanização das atividades produtivas no meio rural, o que gerou um maior desemprego no campo e a grande leva de migrantes em direção às cidades. Após os longos ciclos de urbanização, êxodo rural e metropolização vistos ao longo do século XX, o início do século XXI, sobretudo nessa segunda década, demarca um gradativo processo de descentralização, com o crescimento de metrópoles de médio porte e a desmetropolização quando as cidades médias passam a receber uma maior carga de investimentos, indústrias, empregos e habitantes.

A década de 1960 foi o período em que o Brasil, pela primeira vez, passou a ter uma população predominantemente urbana, ou seja, a maior parte dos habitantes concentrava-se nas cidades. Atualmente, mais de $80 \%$ dos habitantes do Brasil residem em cidades, sendo a maioria em grandes centros urbanos e capitais (IBGE, 2010). Além de um acelerado êxodo rural, a urbanização brasileira contou com um intensivo processo de metropolização - a concentração das populações nas grandes metrópoles, um dos motivos da desigualdade, 
tanto em tamanho das cidades e número de habitantes, quanto em níveis de avanço econômico e ofertas de infraestrutura no espaço urbano brasileiro.

Nesse contexto, internamente as cidades foram marcadas por uma profunda desigualdade, resultado do crescimento desordenado. De um lado uma área planejada, onde há infraestrutura de serviços que permitem um padrão de vida adequado as necessidades; do outro uma área precária, desenvolvidas fora dos planos originais e sem condições de atender as necessidades mais básicas de seus moradores, provocando o agravamento do quadro de exclusão social, com maior visibilidade da marginalização e violência urbana (OLIVEIRA, 2001). Assim, a compreensão do conceito de direito à cidade torna-se essencial atualmente. O debate do direito à cidade no contexto brasileiro é premente e é reivindicado por movimentos coletivos das mais diversas esferas e demandas. De acordo com Rolnik (2013), as cidades brasileiras são cada vez mais, e em vários momentos não apenas palco, mas objeto de intervenções de movimentos coletivos que questionam os atuais modelos de desenvolvimento e as formas de fazer política, bem como a precariedade dos serviços públicos e prioridades dos investimentos por parte do Estado.

O conceito desenvolvido por Henri Lefebvre em 1968 definiu o direito à cidade como um direito de não exclusão da sociedade urbana nas qualidades e benefícios da vida urbana, isto é, uma garantia que pertence a todos os cidadãos. Não é baseado somente ao acesso àquilo que já existe, mas consiste também no privilégio de mudar a cidade, seja coletiva ou individualmente, de acordo com as necessidades dos moradores. Lefebvre descreve a segregação socioeconômica e seu fenômeno de afastamento, referindo-se à tragédia "dos banlieusards", pessoas que são forçadas a viver em guetos residenciais longe do centro da cidade. E sobre essa situação, ele exige o direito à cidade como recuperação coletiva do espaço urbano nos grupos marginalizados às periferias da cidade.

Atualmente, segundo Isensee (2013), o foco da cidade está centrado no mercado, o que inclui novos métodos de produção e novas formas de segregação e exclusão. Há uma ausência de participação na formação da cidade por aqueles que foram excluídos do desenvolvimento econômico, para aqueles que foram deslocados por meio de gentrificação, que segundo Martins (2014), é o processo de mudança imobiliária, nos perfis residenciais e padrões culturais, seja de um bairro, região ou cidade, ou para aqueles que estão sofrendo com políticas de imigração excludentes.

O teórico social David Harvey (2014) delineou a demanda por direito à cidade como uma espécie de pedido para todas as pessoas que vivem na cidade. Segundo Harvey, o direito à cidade é muito mais do que a liberdade individual para acessar os recursos urbanos - é o direito de mudar a nós mesmos, mudando a cidade. Aliás, com frequência, não se trata de um direito individual uma vez que esta transformação depende, inevitavelmente, do exercício do poder coletivo para remodelar os processos de urbanização. A liberdade de criar e recriar nossas cidades e a nós mesmos é dos mais preciosos e mais negligenciado dos direitos humanos. Assim, o direito à cidade revela-se um direito a não exclusão da sociedade urbana em suas qualidades e benefícios. Está diretamente relacionado a mobilidade urbana, ou seja, a facilidade de deslocamento das pessoas e bens na cidade, tendo em vista a complexidade das atividades econômicas e sociais nela desenvolvidas (SEMOB, 2005). 


\section{MOBILIDADE URBANA}

Mobilidade urbana é geralmente utilizada para referir-se ao trânsito de veículos e de pedestres, tanto relacionado ao transporte individual quanto ao uso do transporte coletivo (PENA, 2016). Trata-se de uma demanda derivada das necessidades sociais de trabalho, estudo, cuidados da saúde, visitas à amigos etc. (GOMIDE, 2006).

De acordo com Gomide (2006), a população de baixa renda das grandes cidades do Brasil está sendo privada do acesso aos serviços de transporte público, o qual segundo a Constituição Federal de 1988 é um serviço público de caráter essencial. Ainda segundo Gomide (2006), os serviços de ônibus urbanos são responsáveis por mais de $90 \%$ da demanda total do transporte coletivo no Brasil, na forma predominante de prestação de serviços da iniciativa privada, mas sob planejamento e gestão de órgãos municipais especificamente criados para tal. A ampliação do sistema viário para a fluidez dos automóveis, a medida que a frota continuava crescendo, utiliza a maior parte dos recursos destinados ao transporte urbano individual em detrimento do transporte coletivo, que por sua vez convive com crises relacionadas à incompatibilidade entre custos, tarifas e receitas, à deficiência no planejamento e na gestão dos serviços, e às dificuldades de obter prioridade no uso das vias. Isso se reflete tanto na minoria detentora de meios individuais de transporte, que conta com melhores condições de deslocamentos nas cidades, quanto em na maioria que depende do transporte coletivo, que se vê sem alternativas diante de um transporte público caro e de baixa qualidade.

A oferta inadequada de transporte coletivo, além de prejudicar a parcela mais pobre da população, estimula o uso do transporte individual, que aumenta os níveis de poluição e congestionamentos, demandando utilização de mais recursos para a ampliação e construção de vias (GOMIDE, 2006). Juntamente, a falta de planejamento e controle do uso do solo na organização do desenvolvimento das funções das cidades, provoca a expansão urbana horizontal e o aumento das distâncias e dos custos da provisão dos serviços para as áreas periféricas, onde a oferta se torna deficitária. A origem dessa crise, de acordo com Scaringella (2001), é a disfunção que representa a separação entre as políticas de uso do solo, transporte e trânsito. Mesmo que não estejam escritas ou explícitas, elas acabam sendo a sucessão de ações e omissões que o poder público permite.

Contudo, as atuais condições de mobilidade urbana e de acesso aos serviços de transporte coletivo nas grandes cidades, uma vez que excluem uma parcela significativa da população do acesso aos serviços necessários e às oportunidades que as cidades oferecem, auxiliam a continuidade da pobreza urbana e da exclusão social. Um dos maiores objetivos das políticas sociais, para Gomide (2006), é abrir "portas de saída" para as famílias, ampliando oportunidades e capacidades para superar a condição em que vivem, incluindo as condições inadequadas de mobilidade e acessibilidade urbana. Uma forma de tentar solucionar alguns dos problemas urbanos, inclusive o da mobilidade urbana, seria através dos investimentos do PAC, que será abordado no tópico seguinte. 


\section{O PROGRAMA DE ACELERAÇÃO DO CRESCIMENTO (PAC)}

O PAC foi um programa federal anunciado para o período 2007-2010, nas áreas de transporte, energia, saneamento, habitação e recursos hídricos. Com o investimento em infraestrutura, o objetivo do governo era eliminar os principais déficits que impedem o crescimento econômico, viabilizando o aumento da produtividade das empresas, além do estímulo ao investimento privado e à redução das desigualdades regionais (SALVADOR; RODRIGUES, 2011), e prever medidas institucionais para "melhorias", reacendendo no Brasil o debate a respeito da capacidade de investimentos em infraestrutura gerarem dinamismos regionais ou desequilíbrios socioespaciais (LEITÃO, 2009).

Os recursos iniciais para execução do PAC, segundo Rodrigues e Salvador (2011), tinham origem prevista nos orçamentos das empresas estatais, no orçamento fiscal e da Seguridade Social da União, e provenientes da iniciativa privada. Também propunha medidas de caráter econômico que visam manter a estabilidade econômica e o cumprimento dos acordos internacionais assinados ainda na década anterior. Houve um forte investimento para a divulgação e difusão do PAC como a retomada do Estado como indutor do crescimento e desenvolvimento econômico e social, tendo sido, inclusive, criticado como peça de propaganda governamental e uma das maiores apostas político-eleitorais do governo Lula (RODRIGUES; SALVADOR, 2011).

O PAC é composto por eixos, dividido em cinco blocos: (1) Investimento em infraestrutura, incluindo a infraestrutura social, como habitação, saneamento e transporte; (2) Estímulo ao crédito e financiamento; (3) Melhoria do ambiente de investimento; (4) Desoneração e aperfeiçoamento do sistema tributário; e (5) Implantação de medidas fiscais de longo prazo. O principal bloco do programa sempre foi o investimento em infraestrutura, com investimentos públicos e privados distribuídos em três eixos: (1) Logística (construção e recuperação de rodovias, ferrovias, portos, aeroportos e hidrovias); (2) Energia (investimentos na geração e transmissão de energia elétrica, petróleo, gás natural e combustíveis renováveis); e (3) Infraestrutura social e urbana (investimentos em saneamento, habitação, transporte urbano, Luz para Todos e recursos hídricos) (CHAGAS; CARVALHO; MARQUESAN; 2015).

Em março de 2010, o governo lançou o PAC2, que incorporou ações nas áreas social e urbana, além de ampliar os recursos para a infraestrutura logística e de energia. São seis programas nas áreas de investimento do PAC2: (1) Cidade Melhor; (2) Comunidade Cidadã; (3) Minha Casa, Minha Vida; (4) Água e Luz para todos; (5) Transportes; (6) Energia. Novamente, as ações relacionadas à Energia receberam o maior aporte dos investimentos.

A seguir, será abordado, especificamente, sobre a obra Contorno Norte, realizada com os recursos do PAC.

\section{O CONTORNO NORTE DE MARINGÁ}

Com a grande expansão demográfica da cidade de Maringá a partir da década de 1980 - saltando de 240.000 mil habitantes para aproximadamente 403.000 (IBGE, 2016) 
- a construção civil se desenvolveu muito com a construção de prédios residenciais e condomínios horizontais fechados. Segundo Fontana e Valotta (2012), a expansão do perímetro urbano e a consolidação de Maringá como centro regional trouxe a necessidade adequar a infraestrutura urbana, principalmente viária, para maior fluidez do tráfego. Mas a passagem na Avenida Colombo continuou um problema na mobilidade da cidade, tanto para pedestres quanto para veículos, com congestionamentos diários e inúmeros acidentes. Por isso o DER-PR (Departamento de Estradas e Rodagens do Estado do Paraná) desenvolveu o projeto PAC-Contorno Norte de Maringá (Fig. 1) para "desafogar" a Avenida Colombo com o desvio de carros e caminhões para a periferia da cidade (FONTANA; VALOTTA, 2012).

Figura 1: Localização do Contorno Norte, Maringá, PR (linha em vermelho).

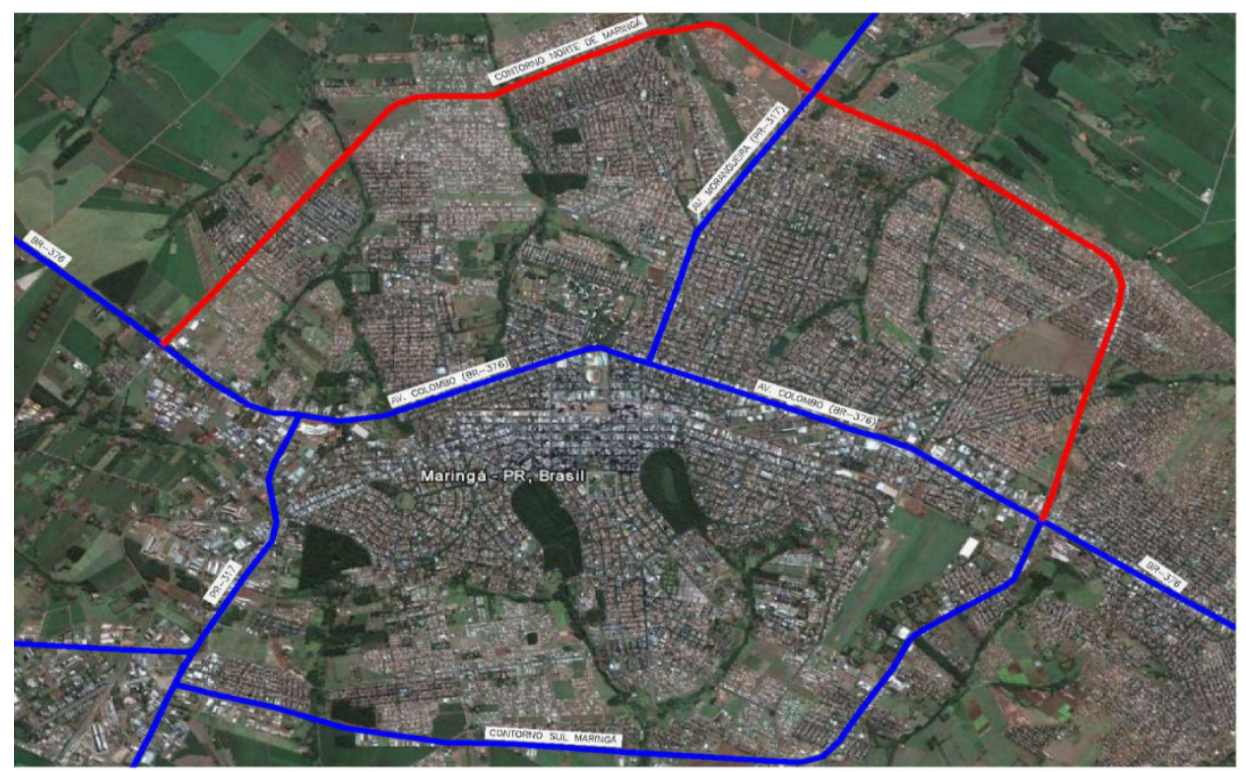

Fonte: Observatório das Metrópoles, 2011.

A obra, que fora pensada na década de 1970, só começou a ser executada no início de 2009 e inaugurada em 2014. Nesse espaço de tempo, Maringá cresceu e se desenvolveu ao ponto de quando se viabilizou a obra, ela já não atendia ao objetivo inicial de desviar o tráfego pesado do espaço urbano, e muito menos para delimitar o perímetro urbano (BORGES; SELA, 2013). Mesmo assim, em 2009, de acordo com Fontana e Valotta (2012), iniciou-se a construção da pista de 17,2 Km de extensão que liga o trevo na divisa entre as cidades de Maringá e Sarandi - localizado no início da Avenida Sincler Sambatti (Contorno Sul), para aliviar o tráfego pesado de caminhões da Avenida Morangueira e Colombo.

Na percepção dos responsáveis pela execução da obra do Departamento Nacional de Infraestrutura de Transporte (DNIT), a obra do Contorno Norte seria de fundamental importância para o contexto viário local e regional, além de desviar o fluxo pesado da cidade pela BR-376, traria inúmeros benefícios à região metropolitana de Maringá, como i) separar o tráfego rodoviário de média e longa distância do tráfego local urbano; ii) facilitar a fluidez do tráfego minimizando o índice de acidentes; iii) diminuir o tempo 
de viagem principalmente dos veículos pesados que transportam cargas; iv) reduzir a emissão de poluentes e ruídos na Avenida Colombo; v) beneficiar a região lindeira atraindo investimentos com a criação de novos loteamentos devido à facilidade de acesso e valorização da área (FONTANA; VALOTTA, 2012).

Hoje, além de não cumprir a função para a qual foi concebida em 2009, constitui-se num contorno que não 'contorna' a cidade, e sim a atravessa pela porção norte, onde uma clara tendência de concentração residencial se estabeleceu. A porção norte é o principal vetor de expansão urbana - induzida pela aprovação da ampliação do perímetro urbano neste sentido pelo poder público. Além disso, o mercado imobiliário tem lançado empreendimentos residenciais no entorno da obra do Contorno Norte, bem como construído equipamentos urbanos, tais como shopping centers e centros universitários (BORGES; SELA, 2013).

A obra do Contorno Norte trouxe, portanto, diversos pontos negativos para a vida cotidiana da população estabelecida em seu entorno e a obra que era vista como uma possível melhoria para a população tornou-se uma barreira limitadora (OLIVEIRA, 2016). Para Fontana e Valotta (2012), ao invés de contornar a cidade de Maringá, ela na verdade separa alguns bairros, o que leva a constituição simbólica e pejorativa do lado de 'cá' e o lado de 'lá', com um setor posicionado no interior das mediações do Contorno Norte, e outro pior, posicionado do lado externo do Contorno Norte, longe do acesso aos equipamentos urbanos básicos e aos eixos comerciais.

Ignorou-se uma série de fatores sociais ao instalar uma obra de tal magnitude em uma área já transposta pela malha urbana, em que parte dos problemas concentrados na Avenida Colombo, como poluição e ruídos, foram apenas transpostos (FONTANA; VALOTTA, 2012). A obra se relacionou mais com os interesses em criar novos espaços de atuação do mercado imobiliário e privilegiar projetos idealizados pelo Poder Público (TOWS, 2015).

\section{O CONJUNTO HABITACIONAL REQUIÃO}

Segundo Fleury e Silva, Savi e Silva (2010), as favelas e cortiços instalados em Maringá nas décadas de 1970 e 1980 foram deslocados posteriormente para a periferia. Então, na década de 1980, boa parte dessas pessoas foram transferidas para conjuntos habitacionais. Por meio da aprovação das Leis Complementares 331/99, 332/99, 333/99, 334/99, 335/99 e 336/99, no final da década de 1990, referentes ao sistema viário, parcelamento do solo, edificações e solo criado, que vigoram até hoje, foram implantados 30 conjuntos habitacionais, inclusive o Conjunto Habitacional Requião (Fig. 2), sendo um dos maiores conjuntos implantados na cidade. O que trouxe o embelezamento da cidade, mas também colaborou para intensificar a segregação residencial de pessoas com menor poder aquisitivo. 
Figura 2: Localização do Conjunto Habitacional Requião, Maringá, PR.

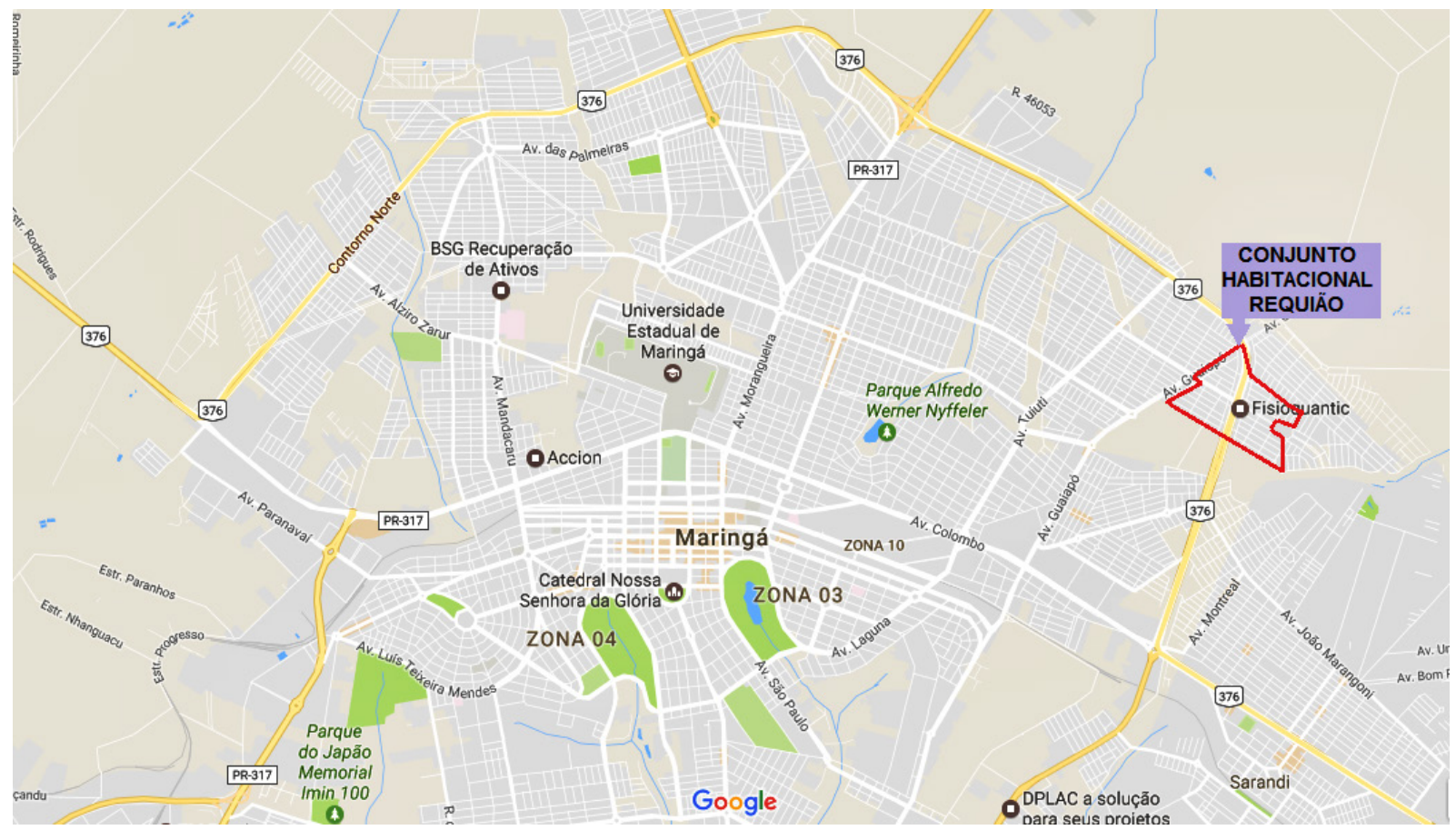

Fonte: adapt. de Google Maps, 2016.

O Conjunto Habitacional Requião, localizado na Zona Norte da cidade, foi inaugurado na década de 1990, através de uma parceria entre a prefeitura e o Governo do Estado, por meio da Companhia Paranaense de Habitação (COHAPAR). O nome dado ao bairro homenageia o governador Roberto Requião (PMDB), que até então estava no seu primeiro mandato no governo paranaense e aliado político do prefeito, da época, Said Ferreira. Sua paisagem é típica de um bairro comum de Maringá, onde as ruas e as calçadas são largas e arborizadas (DAIBERT, 2007). Dividido em quatro partes, recebeu seus primeiros moradores

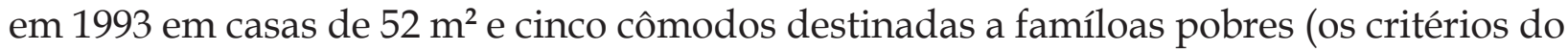
programa habitacional exigiam que o responsável da família estivesse desempregado e tivesse, no mínimo, cinco filhos). Até o final do ano seguinte, sem o mesmo rigor, todas as 1.166 casas estavam habitadas (DAIBERT, 2007). De acordo com o censo de 2010, a população era de 26.114 habitantes, num total de 7.510 famílias. Segundo Rodrigues e Moura (2009), há um déficit local de 664 moradias, mostrando que o Conjunto Habitacional Requião, por ser um bairro popular, favorece a ocupação de mais de uma família no mesmo domicílio.

O conjunto Requião é separado por ruas dos conjuntos Guaiapó, Moradia dos Ipês e Jardim Paulista, mas por se sobressair, o Requião acaba passando a ideia de tratar-se de um mesmo conjunto (DAIBERT, 2007). Juntamente com o conjunto Guaiapó, eles representam as maiores áreas urbanas precárias e periféricas da cidade de Maringá, que há mais de 15 anos aguardam pela democratização de acesso à cidade (FLEURY e SILVA; SAVI; SILVA, 2010). 


\section{REFLEXOS DA OBRA CONTORNO NORTE NO BAIRRO}

No Conjunto Habitacional Requião os entrevistados afirmaram que a obra Contorno Norte trouxe benefícios e malefícios, sendo que se sentiram mais prejudicados do que beneficiados.

Analisando um dos pontos positivos proporcionado ao comércio de maneira geral, após a construção do Contorno Norte houve o aumento no fluxo de veículos e de pessoas na Avenida Franklin Roosevelt, central no conjunto, como afirma o entrevistado E2: "Antes de ter o contorno, todo lugar tinha saída para os bairros, Guaiapó, Paulista, saiam pela rua de trás, depois que teve o contorno a saída é só ali, ou Sarandi, ou lá na estrada Guaiapó, uns 2 km daqui. Só tem essas saídas pra cá, e a saída que mais o pessoal utiliza é essa, então todo mundo tem que passar por aqui, e acaba parando por aqui. Eu creio que para algumas pessoas podem até ter sido prejudicadas, mas eu não tenho o que reclamar não. O caminho já é aqui, tem que passar por aqui."

Como as pessoas precisam passar por essa avenida, de carro ou a pé, por ser uma das únicas vias de entrada e saída do bairro, o aumento no fluxo de pessoas pode ter levado a um possível aumento das vendas, porém este não é únco determinante no aumento e/ ou a diminuição das vendas, uma vez que o país, atualmente, vem sofrendo problemas econômicos e políticos, como pontuou o entrevistado E4, sobre as vendas do comércio após a construção da obra: "Tá começando a reagir (as vendas), mas não é bem a obra agora, o pessoal tem que se adequar do que está hoje né, se o cara não pode andar com dois tem que andar com um, então o brasileiro tem essa mania de se adaptar a situações. Então, eu acho a queda das vendas de modo geral, não é só no nosso caso, o comercio todo, é a própria situação do país né, a situação tá bem difícil".

Os comerciantes afirmaram claramente que, durante a construção da obra, as vendas diminuíram, já que a passagem principal para "o lado de cá" do bairro ficou interditada, e os clientes que moravam lá, deixaram de ir ao comércio, como relembra o entrevistado E1: "No começo ficou muito tempo enrolando a construção, teve um tempo que ficou interditado, não tinha passagem e acaba atrapalhando, porque não desce carro, não passa carro, ofluxo diminuiu bastante, assim, diminuiu o movimento de clientes." Percebe-se que o Poder Público não levou em consideração o tempo que a passagem ficou interditada na avaliação de impacto sobre os moradores.

As expressões, usadas entre eles, "lado de cá" e "lado de lá" mostra o resultado da divisão imposta pela obra, que deixou clara a barreira criada entre os moradores, como afirma o entrevistado E7: "(...) ficou muito dividido o bairro por causa da mobilidade ali, que ficou ruim para passar tanto carro como pedestre". Essa situação mostra a segregação social existente no conjunto após a construção da obra, segundo a concepção de Lefebvre (2001) de negação do direito à cidade. O viaduto que liga "um lado e outro", que passa por cima do Contorno Norte, é o principal transtorno apontado pelos moradores do Conjunto Habitacional Requião (Fig. 3). No projeto do viaduto, segundo os moradores, este deveria ter sido construído como continuação da Avenida Franklin Roosevelt, sendo esta de mão dupla e pista dupla. No entanto o viaduto foi construído como pista simples, não atendendo a demanda do tráfego do bairro, que aumentou ainda mais ao se tornar uma das únicas 
passagens mais próximas, como relata o entrevistado E2: "O pessoal reclama muito porque foi feito uma construção com só uma mão (pista simples), que teria que ser duas, o problema é esse, que causa tumulto e muito acidente (...). Vem carro de lá, vem carro daqui, vira, contorna, os que vem de lá do lado de Sarandi, o fluxo daqui é um perigo".

Assim, a construção não foi feita como o projeto apresentado aos moradores: “(...) na verdade essa obra era para ter continuado a avenida por cima do contorno, ter feito duas pistas, mas fizeram uma só, então estreitou né, ficou uma pista simples" (E1). Um dos princípios do Estatuto da Cidade, segundo Oliveira (2001), é a gestão democrática da cidade que garante a participação da população nas decisões de interesse público, desde a elaboração, implementação e avaliação. Assim, não se deve apenas consultar a opinião da população, mas sim, segundo Barros, Carvalho e Montandon (2010), garantir instancias efetivamente consultivas e deliberativas desde a elaboração até a destinação dos recursos públicos. No caso do Conjunto Habitacional Requião tal direito foi ignorado, uma vez que os moradores alegam que não estavam cientes da alteração do projeto, nem tiveram uma exposição do Poder Público sobre os motivos que levaram à essa alteração. Segundo os entrevistados, não foi realizada qualquer reunião para explicar como a obra seria realizada, houve apenas o aviso do momento em que seria iniciada.

Figura 3: viaduto do bairro Conjunto Habitacional Requião, Maringá, PR.

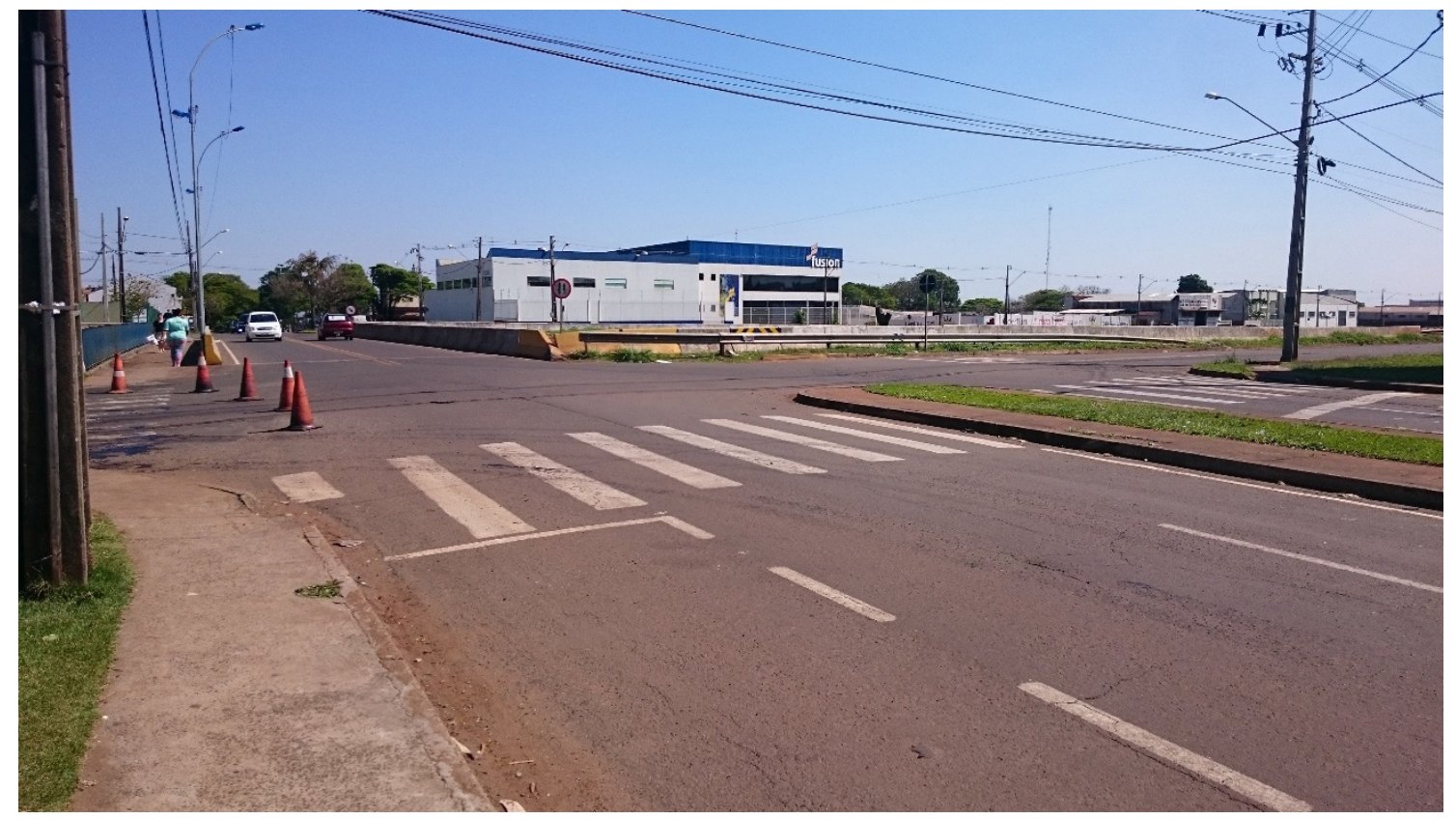

Fonte: Arquivo pessoal.

O contorno causou grande concentração de tráfego de veículos na região do viaduto, pelo fato já citado de ter sido construído com pista simples, e principalmente pela falta sinalização no local, como afirma o entrevistado E2: "Falta sinalização, foi feito 'uma perna só' (pista simples), uma deficiência ali né, teria que ter as duas mãos né, não sei se é assim mesmo, eu creio que não. Mas tinha que ter uma sinalização melhor, não sei, alguma coisa que melhorasse ali porque é perigoso. Igual lá embaixo na Guaiapó, eles colocaram sinaleiro lá, ficou legal né, o 
pessoal que vai, para, abriu, o outro vai. Mas aqui não, talvez porque é bairro né, eles não ligam muito de fazer isso né".

Percebe-se através da fala do entrevistado E2 o descaso do Poder Público com o Conjunto Habitacional Requião, como se a situação que os moradores estão enfrentando não fosse relevante o suficiente para a implantação de melhorias. Rolnik (1995) afirma que desde a primeira forma de gestão, percebe-se a dinâmica de exploração e privilégio em relação à administração do território urbano, onde as cidades se sujeitam à forma de organização de relação política, agindo de acordo com os interesses públicos.

O transtorno causado pelo Contorno Norte tem dificultado a vida dos moradores, principalmente nos horários de deslocameto para o trabakho e escola, por volta das 6 e 7 horas da manhã, e igualmente por volta das 18 e 19 horas da noite, onde o fluxo de veículos e pedestres é maior, como afirma o entrevistado E2: "Sete horas da manhã e sete horas da noite pra você cruzar aquilo ali, não é fácil não, é perigoso, tem que prestar bastante atenção, já aconteceu bastante acidente".

Acidentes nessa área do bairro acontecem com frequência fazendo com que os moradores sintam medo de atravessar o viaduto pela falta de sinalização no local. Há uma passagem de pedestres somente em um lado do viaduto, e com o grande fluxo no tráfego, as pessoas evitam atravessar ou passar próximo ao local, como afirma o entrevistado E1: "(...) eu escuto senhoras de idade dizer que tem medo de atravessar ali, ficou muito difícil atravessar. Esses dias até eu fui pra academia lá embaixo ("do outro lado") de a pé, eu senti dificuldade para atravessar, eu ainda comentei com a minha amiga "nossa, a gente que é novo, que enxerga bem, que anda bem, se atrapalha pra passar, imagina uma pessoa de idade". Porque ficou difícil pra 'caramba', vem carro de todos os lados, não tem sinalização direito, ninguém sabe quem deve parar, quem vai, quem fica, ainda sente um pouco, porque tem gente que fala que sente vontade de vir aqui, mas tem medo de atravessar de a pé".

Em relação às dificuldades da mobilidade urbana, de forma ainda mais intensa os pedestres, o projeto do Contorno Norte contou com a construção de passarelas de travessia a cada 700 metros ao longo de sua extensão. $O$ engenheiro da obra, entrevistado em Rodrigues (2011), a obra contribui para a mobilidade urbana tanto no sentido de Norte-Sul como Leste-Oeste da cidade e as dificuldades foram solucionadas com a construção dessas passarelas para pedestres, sendo que a implantação dessas estruturas não foi arbitrária, mas seguiu as normas do DNIT. No entanto, mesmo com essa afirmação do engenheiro da obra, as passarelas não solucionaram os verdadeiros problemas de mobilidade da população, incluindo os moradores do bairro Conjunto Habitacional Requião, como afirma o entrevistado E2: "A passarela só tem no outro bairro, divisa com Liberdade (bairro) e um outro (bairro) lá, não tem condições, o certo seria que tivesse um aqui também já que não tem semáforo, nada ali né".

E o entrevistado E1 ainda aponta uma situação diária em relação aos obstáculos da mobilidade urbana no bairro: "A passarela que eu vejo é ali na Liberdade, é muito longe, ninguém atravessa naquela passarela. Meu marido trabalha ali em Sarandi, então eu vou direto levar ele no serviço, a gente comenta direto, o que você vê de criança atravessando naquele contorno, de monte. Eu falo para o meu marido "logo vai morrer criança ali", mas é muita criança, passa uma atrás da 
outra com as 'mochilinhas' nas costas, aí pulam aquela barra de proteção, vão tudo de a pé, passa ali, porque a passarela é lá na frente."

Essa situação não condiz com o que engloba o real sentido de mobilidade urbana, que segundo Gomide (2006), a mobilidade urbana é a demanda derivada das necessidades sociais da população, como trabalhar, estudar, cuidar da saúde. E o bairro vem sofrendo por conta dessas dificuldades que tem como origem, de acordo com Scaringella (2001), a separação entre as políticas de uso de solo, transporte e trânsito, onde, o poder público acaba por permitir a omissão das consequências de suas ações.

Contudo, a preocupação mostrada através das entrevistas vai além da preocupação dos comerciantes a respeito do aumento e/ou a diminuição das vendas, mas abrange o fato de que essa situação em que o bairro se encontra influencia muito a segurança dos moradores, a vida social das pessoas que ali residem, como afirma o entrevistado E8: “ $O$ que a gente vê que acontece muito ali é acidente né, acidente que viu muita gente morrer, isso é consequência daquele negócio muito estreito, eu acho que ali tinha que alargar, colocar um semáforo, porque ali são várias mãos (pistas) que vai numa via só, (...), subindo, que vem da esquerda, que vem da direita, e que usa só aquela "pontezinha" ali né, eu acredito que em perda de vida, aí sim, não é que afetou a gente (os comerciantes) mas afeta os moradores da região né, porque a gente vê acidente direto ali, acontecendo ali."

E como prevê o Estatuto da Cidade é direito dos cidadãos o uso da propriedade urbana a favor do bem coletivo, segurança e bem-estar, entretanto, essa regulamentação está sendo negada aos moradores do bairro Conjunto Habitacional Requião.

\section{CONCLUSÕES}

Após as análises foi possível compreender que a obra trouxe consequências negativas para a população residente no Bairro estudado, uma vez que houve alteração no projeto inicial, e viaduto construído que dá passagem para o bairro foi feito em pista simples e não em pista dupla, já que era para ter sido construído como continuação da Avenida Franklin Roosevelt, no qual as vias são duplicadas. Essa situação impactou diretamente na mobilidade urbana do bairro, o tráfego de veículos aumentou bastante, causando congestionamentos nos 'horários de pico', além de ocorrer acidentes com frequência. Outro motivo é a falta de sinalização, fazendo com que haja mais insegurança no local, afetando tanto o tráfego de automóveis, quanto de pedestres. Além disso, não houve participação da população no processo de decisão sobre a construção da obra, conforme dita a lei para obras de grande impacto.

Os resultados obtidos comprovam os argumentos de autores como Fontana e Valotta (2012), Rodrigues (2011), Borges e Sela (2013) e entre outros, que mostram que o Poder Público pode até eventualmente resolver necessidades como moradia e transporte, porém, é negado à população a construção da sua própria cidade, negando-lhes o direito à cidade, isto é, o direito de inclusão social, das qualidade e benefícios que a vida urbana oferece (LEFEBVRE, 2001). O direito à cidade está relacionado diretamente com as condições 
adequadas de mobilidade urbana, e quando esse não é observado pelo Poder Público, pode ocorrer a exclusão social de uma parcela significativa da população, se contrapondo ao real objetivo da mobilidade urbana, que é ampliar as oportunidades e capacidades de superar as condições em que vivem, abrindo-lhes "portas de saída" (GOMIDE, 2006). A análise das entrevistas realizadas possibilitou a compreensão de que a obra impactou negativamente a vida dos moradores do bairro Conjunto Habitacional Requião.

Esse artigo alcançou o objetivo proposto, apresentando uma análise e compreensão dos reflexos que uma grande obra pode trazer para a população local e da cidade como um todo. Sugere-se para trabalhos futuros a abrangência de outros bairros fronteiriços à obra Contorno Norte na cidade de Maringá, bem como de outras cidades do país que tiveram uma construção de magnitude similar, para assim, analisar quais os reflexos foram gerados para a população, mostrando os diversos fatores sociais ignorados pelo Poder Público.

\section{REFERÊNCIAS}

ANDRADE, Carlos Roberto Monteiro de; CORDOVIL, Fabiola Castelo Souza. A cidade de Maringá, PR. o plano inicial e as "requalificações urbanas". Actas Del X Coloquio Internacional de Geocrítica. Barcelona: Universidad de Barcelona, 2008. Disponível em: <http://www.ub.edu/geocrit/-xcol/55.htm>. Acesso em: 20 jun. 2018.

BARROS, Ana Maria Furbino Bretas; CARVALHO; Celso Santos; MONTANDON, Daniel Todtmann. O Estatuto da Cidade comentado. In: CARVALHO, Celso Santos; ROSSBACH, Anaclaudia. (Orgs). O Estatuto da Cidade: comentado. São Paulo: Ministério das Cidades/Aliança das Cidades, 2010.

BORGES, William Antônio; SELA, Vilma Meurer. Cooperação intergovernamental e produção do espaço urbano: o alinhamento entre mercado, financiamento público, política eleitoral e obras públicas na cidade de Maringá. In: ENCONTRO NACIONAL DOS PROGRAMAS DE PÓS-GRADUAÇÃO EM ADMINISTRAÇÃO, 37, 2013, Rio de Janeiro. Anais... Rio de Janeiro: ANPAD, 2013. 1 CD-ROM.

CHAGAS, Priscilla Borgonhoni; CARVALHO, Cristina Amélia; MARQUESAN, Fábio Freitas Schilling. Desenvolvimento e dependência no Brasil nas contradições do Programa de Aceleração do Crescimento. Organizações \& Sociedade, v. 22, n. 73, p. 269-289, abr./jun., 2015.

COELHO, Kellen Silva. A resistência à nova proposta de Plano Diretor apresentada pela Prefeitura Municipal de Florianópolis: uma análise das práticas alternativas de organizar. Florianópolis, 2012. Tese (Doutorado em Administração) - Universidade Federal de Santa Catarina, UFSC.

CORRÊA, Roberto Lobato. O Espaço Urbano. São Paulo: Ática, 1999.

DAIBERT, Juliana. Simplicidade, a marca do Conjunto Requião, 2007. Disponível em: http://maringa. odiario.com/maringa/noticia/181876/simplicidade-a-marca-do-conjuntorequiao. Acesso em: 24 jun. 2016.

FLEURY E SILVA, Beatriz; SAVI, Elise; SILVA, Ricardo Dias. A configuração socioespacial do aglomerado metropolitanoSarandi-Maringá-Paiçandu a partir da moradia popular: da gênese a atualidade. Observatório das Metrópoles. Maringá, 2010. Disponível em: https://docplayer.com.br/31819306-A-configuracaosocioespacial-do-aglomerado-metropolitano-sarandi-maringa-paicandu-a-partir-da-moradia-popular-dagenese-a-atualidade.html. Acesso em: 09 dez. 2016.

FONTANA, Felipe; VALOTTA, Fernanda Martins. PAC “Contorno Norte”: a cidade de Maringá e o aumento do processo de segregação socioespacial de sua região metropolitana. In: SEMANA DE HISTÓRIA, 18, 2012, Maringá. Anais ... p. 1-15.

GOMIDE, Alexandre Ávila. Mobilidadeurbana, iniquidadee políticas sociais. Repositório do Conhecimento do IPEA, Políticas sociais - acompanhamento e análise, v. 12, 2006. Disponível em: http:/ / repositorio.ipea. 
gov.br/handle/11058/4511. Acesso em: 22 jun. 2016.

HARVEY, David. Cidades rebeldes: do direito à cidade à revolução urbana. São Paulo: Martins Fontes, 2014.

IBGE - Instituto Brasileiro de Geografia e Estatística. Censo 2010. Disponível em: http:/ /www.ibge.gov.br. Acesso em: 10 out. 2019.

IBGE - Instituto Brasileiro de Geografia e Estatística. Estimativas 2019. Disponível em: https://cidades. ibge.gov.br/brasil/pr/maringa/panorama. Acesso em: 10 out. 2019.

ISENSEE, Patrick. O que é direito à cidade? 2013. Disponível em: http://rioonwatch.org.br/?p=7921 Acesso em: 25 jun. 2016.

LEFEBVRE, Henri. O direito à cidade. São Paulo: Centauro, 2001.

LEITÃO, Karina Oliveira. A dimensão territorial do Programa de Aceleração do Crescimento: um estudo sobre o PAC no estado do Pará e o lugar que ele reserva à Amazônia no desenvolvimento do país. São Paulo, 2009. Tese (Doutorado em Arquitetura e Urbanismo) - Universidade de São Paulo, USP.

MARTINS, Andréia. Gentrificação: o que é e de que maneira altera os espaços urbanos. 2014. Disponível em: http://vestibular.uol.com.br/resumo-das-disciplinas/atualidades/gentrificacao-o-que-e-e-de-quemaneira-altera-os-espacos-urbanos.htm. Acesso em: 26 jun. 2016.

OLIVEIRA, Isabel Cristina Eiras de. Estatuto da Cidade para compreender... Rio de Janeiro: IBAM/ DUMA, 2001. Disponível em: http://polis.org.br/wp-content/uploads/estatuto_cidade_compreender. pdf. Acesso em: 11 maio 2016.

OLIVEIRA, J. S. O plano diretor nos municípios de Maringá, Paiçandu e Sarandi: planejamento público estratégico. Especialização em Gestão Pública Municipal - Universidade Estadual de Maringá, 2011.

OLIVEIRA, Adriano Aparecido de. Intervenções urbanas a partir de investimentos do Programa de Aceleração do Crescimento (PAC): a reterritorialização dos moradores do entorno da obra Contorno Norte de Maringá - PR. Maringá, 2016. Dissertação (Mestrado em Administração) - Universidade Estadual de Maringá, UEM.

PAC. Programa de Aceleração do Crescimento. Brasília, 2015. Disponível em: http://www.pac.gov.br/. Acesso em: 10 mai. 2016.

PENA, Rodolfo Alves. Mobilidade urbana no Brasil. Brasil Escola, 2016. Disponível em http:/ / brasilescola. uol.com.br/geografia/mobilidade-urbana-no-brasil.htm. Acesso em: 23 jun. 2016.

PENA, Rodolfo Alves. Espaço urbano brasileiro. 2014. Disponível em: http://www.mundoeducacao. com/geografia/o-espaco-urbano-brasileiro.htm. Acesso em: 27 maio 2016.

RODRIGUES, Ana Lúcia. Características do processo de urbanização de Maringá, PR: uma cidade de "porte médio". Cadernos Metrópole, n.12, p. 95-121, 2004.

RODRIGUES, Ana Lúcia; MOURA, Rosa. Como andam Curitiba e Maringá. Observatório das Metrópoles, 2009.

RODRIGUES, Ana Lúcia. PAC Maringá Contorno Norte: conformações socio-morfológicas e segregação social. Observatório das Metrópoles, 2011.

RODRIGUES, Ana Lúcia; SALVADOR, Evilásio. As implicações do Programa de Aceleração do Crescimento (PAC) nas Políticas Sociais. SER Social, Brasília, v. 13, n. 28, p. 129-156, jan./jun. 2011.

ROLNIK, Raquel. O que é cidade. São Paulo: Brasiliense, 1995.

ROLNIK, Raquel. As vozes das ruas: as revoltas de junho e suas interpretações. In: Cidades rebeldes: passe livre e as manifestações que tomaram as ruas do Brasil. São Paulo: Boitempo/ Carta Maior, 2013. p. 7-12.

SANTOS, Milton. Técnica, espaço e tempo: globalização e o meio técnicocientifico informacional. São Paulo. HUCITEC, 1998.

SCARINGELLA, Roberto Salvador. A crise da mobilidade urbana em São Paulo. São Paulo em perspectiva, São Paulo, v. 15, n. 1, 2001. Disponível em: http://www.scielo.br/scielo.php?pid=S0102- 
$88392001000100007 \&$ script=sci_arttext\&tlng=pt. Acesso em: 22 jun. 2016.

SEMOB - Secretaria Nacional de Transporte e Mobilidade Urbana do Ministério das Cidades. Estatuto da mobilidade urbana: texto básico de fundamentação do anteprojeto de lei - Documento para discussão. Brasília, 2005.

STAHLHOEFER, Julia Marcon Costa; RODRIGUES, Ana Lucia. (Des)articulações territoriais urbanas: a privatização de áreas públicas. In: SIMPÓSIO PARANAENSE DE ESTUDOS CLIMÁTICOS, 2, 2010, Maringá. p. 1-15.

TOWS, Ricardo Luiz. Grandes projetos urbanos como reprodução da lógica do capital em Maringá (PR). Maringá, 2015. Tese (Doutorado em Geografia) - Universidade Estadual de Maringá, UEM.

Data de submissão: 18/ abr./ 2017

Data de aceite: 04/ jul./ 2019 